\section{Evaluation of Breast Cancer Radiation Therapy Techniques in Outfield Organs of Rando Phantom with Thermoluminescence Dosimeter}

\author{
Behmadi M. ${ }^{1}$, Gholamhosseinian H. ${ }^{2}$, Mohammadi M. ${ }^{3}$, Na- \\ seri Sh. ${ }^{2}$, Momennezhad M. ${ }^{4}$, Bayani Sh. ${ }^{1}$, Bahreyni Toossi \\ M. T.2*
}

\begin{abstract}
Background: Given the importance of scattered and low doses in secondary cancer caused by radiation treatment, the point dose of critical organs, which were not subjected to radiation treatment in breast cancer radiotherapy, was measured.
\end{abstract}

Objective: The purpose of this study is to evaluate the peripheral dose in two techniques of breast cancer radiotherapy with two energies.

Material and Methods: Eight different plans in two techniques (conventional and conformal) and two photon energies ( 6 and $15 \mathrm{MeV}$ ) were applied to Rando Alderson Phantom's DICOM images. Nine organs were contoured in the treatment planning system and specified on the phantom. To measure the photon dose, fortyeight thermoluminescence dosimeters (MTS700) were positioned in special places on the above nine organs and plans were applied to Rando phantom with Elekta presice linac. To obtain approximately the same dose distribution in the clinical organ volume, a wedge was used on planes with an energy of $6 \mathrm{MeV}$ photon.

Results: Point doses in critical organs with 8 different plans demonstrated that scattering in low-energy photon is greater than high-energy photon. In contrast, neutron contamination in high-energy photon is not negligible. Using the wedge and shield impose greater scattering and neutron contamination on patients with low-and high-energy photon, respectively.

Conclusion: Deciding on techniques and energies required for preparing an acceptable treatment plan in terms of scattering and neutron contamination is a key issue that may affect the probability of secondary cancer in a patient.

\section{Keywords}

Photon Dose Measurement, Radiation Therapy, Breast Cancer, Thermoluminescence Dosimeter, Rando Phantom

\section{Introduction}

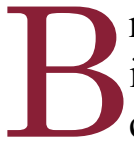
reast cancer is one of the most common cancers among women in the world [1-3]. Early diagnosis and radiotherapy treatment can decrease the mortality rate [4-6] and increase the survival rate of these patients $[6,7]$. Despite the advantages of radiotherapy for cancer treatment as one of the third treatment modalities, radiotherapy is a "two-edged swords" that may cause cancer [8-10]. Therefore,
${ }^{1}$ Department of Medical Physics, Faculty of Medicine, Mashhad Univer-

sity of Medical Sciences,

Mashhad, Iran.

${ }^{2}$ Medical Physics Re-

search Center, Mashhad

University of Medical Sci-

ences, Mashhad, Iran.

${ }^{3}$ Royal Adelaide Hospital,

Department of Medi-

cal Physics, Adelaide,

Australia.

${ }^{4}$ Nuclear Medicine Research Center, Mashhad University of Medical Sciences, Mashhad, Iran

Corresponding author: M. T. Bahreyni Toossi Mashhad University of Medical Sciences, Medical Physics Research Center, Mashhad, Iran E-mail: bahreynimt@ mums.ac.ir

Received: 6 December 2018 Accepted: 22 December 2018 
dose distribution in critical organs, which are outside the treatment fields, is a crucial matter. Absorbed dose in these organs are due to the photon scattering. The main sources of photon scattering are head leakage, patient (phantom) and secondary collimator scattering [11]. Given the importance of absorbed dose caused by photon and electron scatter and secondary cancer caused by radiation, authors tried to measure out-field critical organ dose in some treatment plans with different techniques [12-16]. Banaee et al. in 2014 [12] measured the peripheral dose for bladder, rectum and prostate cancer in the phantom and 27 patients. They conducted their measurement using two photon energies with Thermoluminescence dosimeters (TLD). Authors assessed the necessity of a testicular shield for high and low energies. Cyriac et al. in 2015 [13] evaluated the peripheral dose for prostate cancer by comparing the treatment planning system (TPS), ionizing chamber and TLDs measurement of the two techniques (3D-Conformal radiation therapy and Intensity modulated radiation therapy). Based on their evaluation, the inaccuracy of TPS calculation for outfield organ dose was proved. Thermoluminescence dosimeters (TLD) was approved as an acceptable tool for evaluating and monitoring the absorbed dose in patients' organs in different radiotherapy treatment with the same articles [13, 17-19]. Based on the literature review, there were not any articles which compare the nine organs' photon absorbed dose in two techniques and two energies for breast cancer radiation therapy. Therefore, the authors in this study decided to evaluate the organs' absorbed dose in eight different plans.

The goal of this study is to measure outfield dose of critical organs in breast cancer radiotherapy in Rando phantom. Treatment was administered using two different techniques (conventional and conformal) and two photon energies ( 6 and $15 \mathrm{MeV}$ ) and assessments were made by comparing point doses in nine organs measured by the thermoluminescence dosimeter.

\section{Material and Methods}

\section{Treatment plans for breast cancer}

To evaluate and compare point dose of the outfield organs in breast cancer, eight different plans containing two techniques (conventional and conformal) and energies (6 and $15 \mathrm{MeV}$ ) were applied along with ISO gray treatment planning system (version 4.2.3.50L) to Rando phantom's DICOM (Digital Imaging and Communications in Medicine) images. The Rando Alderson phantom (Radiology Support Devices (RSD), United Kingdom) DICOM images were taken in the radiology department and the radiation treatment was administered in radiotherapy department using Elekta Precise linear accelerator (Stockholm, Sweden) in Emam Reza hospital of Mashhad, Iran. Prior to the plan, nine organs (right and left lenses, thyroid, right and left lung, right and left kidney, spinal cord, heart and liver, bladder, rectum, uterine) were contoured by the radiation oncologist on DICOM images in TPS and then planning was performed. Plans applied to the phantom were as follows: 2 opposed tangential fields; 2 opposed tangential fields together with super clave and postaxial treatment field using two different energies and techniques. The details of each plan are given in Table1. Attempts were made to maintain other parameters of treatment plans constant to have reasonable dose distribution and acceptable treatment plans. In all plans, the prescribed dose was 50 cGy in 25 fractionations. Figure 1 illustrates the CT (computed tomography) simulation of the Rando phantom and one of its plans (Conventional+supra+postaxilla, $15 \mathrm{MV}$ ) in ISOgray TPS.

TLDs are located in special positions which are determined and embedded in Rando phantom. In this study, to measure the peripheral photon dose in organs, MTS-700 TLDs (TLD Poland, Krakow, Poland) purchased from Poland Company were used to measure point 


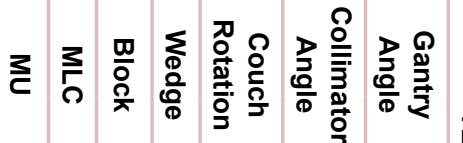

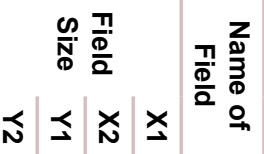

끈

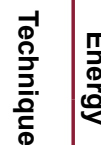

㕝るる兽 0 \&

虑 る

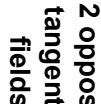

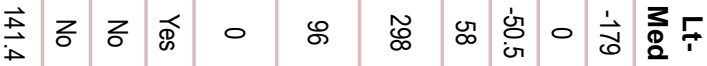

状る る

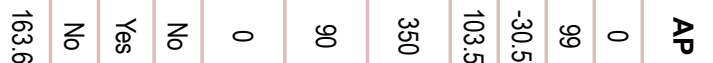

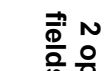

言 흥ㅎํㅇ



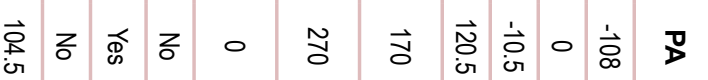

줄

高

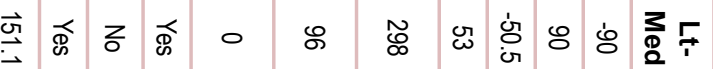

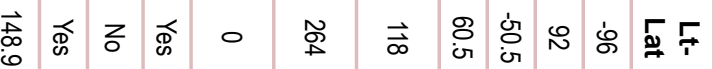

$\Rightarrow \overrightarrow{\underline{m}} \stackrel{0}{0}$





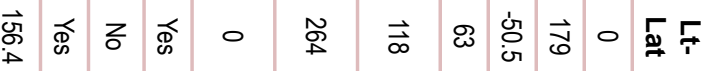

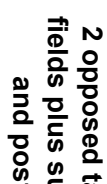

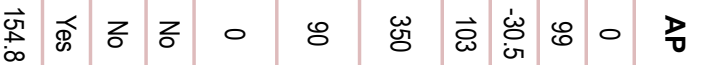

兽

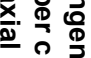

离竞

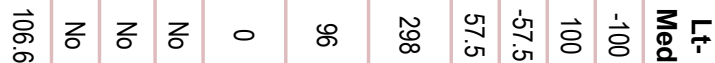

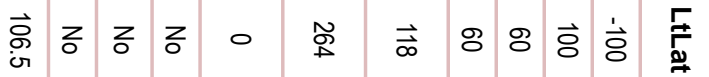



离

$\overrightarrow{\vec{\omega}}$
$\infty$



产る る

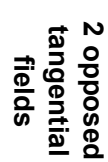

言希るる。

突布るる

$\overrightarrow{0}$ 希 る

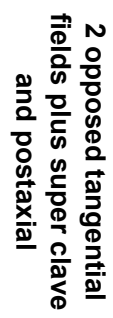

㪯 $\frac{\overline{9}}{\frac{9}{10}}$

ס

,

垔

光

을

定

定

(

吕

离

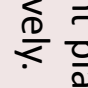

象

$\frac{8}{8}$

$\frac{8}{\circ}$

$\mid$

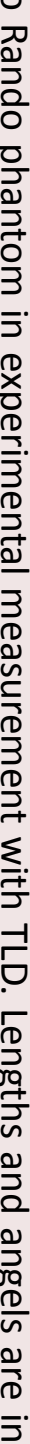


dose in organs. Before using the TLDs, they were calibrated with the photon mode of Elekta precise linac (6 MeV energy) based on the calibration protocols of these TLDs obtained from the company and then point doses of outfield organs were calculated. Some of Rando phantom slices and TLDs' positions in these slices are illustrated in Figure 2.

\section{Calibration of TLD}

Calibration was implemented in three steps: In the first and second steps, the reader cali- bration factor (RCF) was determined and in the third step, element correction coefficient (ECC) was computed. In the first step, at least $10-15 \%$ of total TLDs should be selected as representative. Thus, 15 TLDs from 50 TLDs were chosen randomly and irradiated to achieve a uniform dose under the range of dose distribution which is linear (less than one gray (1 Gy) is acceptable). TLDs were read by a Harshaw TLD reader ( Model 3500- Thermo electron, Solon, $\mathrm{OH}$ ) and the dimensions provided by the TLD reader for each TLD at this
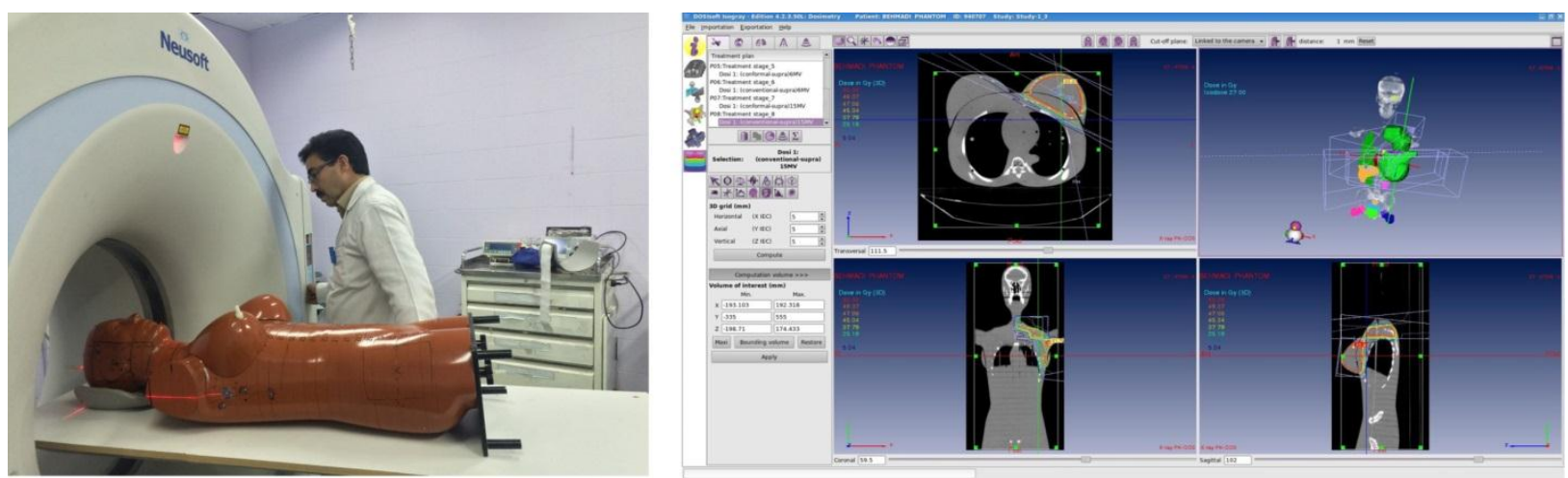

Figure 1: (a) CT simulation of the Rando phantom. (b) One of plans (Conventional+ supra+ postaxilla, 15MV) in ISOgray TPS.
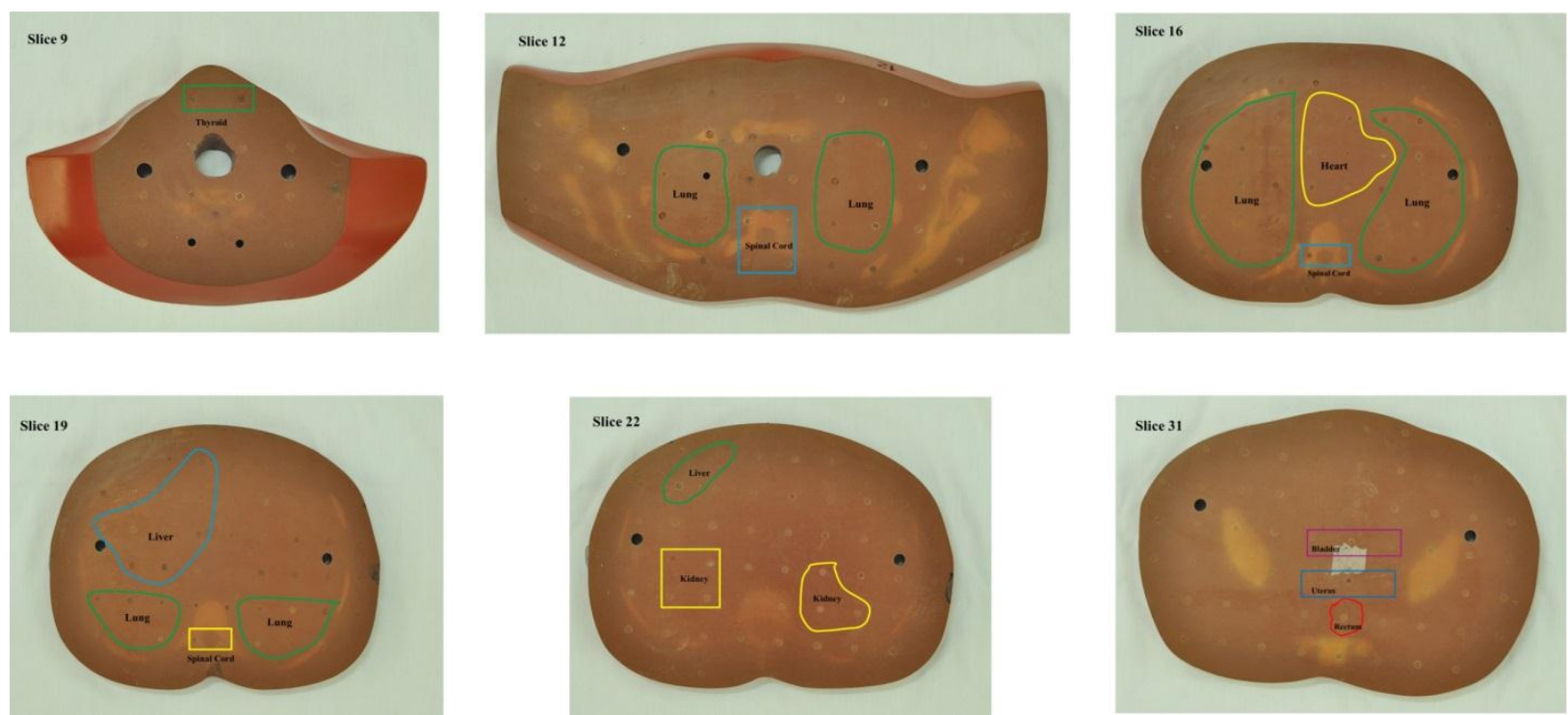

Figure 2: Rando phantom slices and TLDs position in some of slices. 
stage were in nano-coulomb $(\mathrm{nC})$. The average of these numbers was calculated and ECC of each TLD was determined using the following formula:

Element correction coefficient(ECC) for representative $T L D s=$ Average of $n C$ for representatives $T L D(n C) / n C$ for each $T L D$

In this stage, all TLDs were introduced to the TLD reader.

In the second step, representative TLDs were irradiated by a homogeneous and specific dose. The average $\mathrm{nC}$ read by the reader was calculated and RCF was computed by the following formula:

Reader calibration factor (RCF) for representative $T L D s=$ Average $n C$ for representatives TLD (nC)/certain (specified) dose (Gy)

In this stage, the reader sensitivity and unit conversion factor are determined.

The third step involved exposing all TLDs to a homogeneous and distinctive dose to determine ECC for each TLD. Here, the unite used by the reader is gray since $\mathrm{nC}$ was divided by RCF as follow:

$$
n C / R C F=\text { Dose }(G y)
$$

Therefore, ECC will be computed by dividing the distinctive dose by the above numbers for each TLD.

distinctive dose/Dose $(G y)=E C C$ (for each TLD)

Based on the TLDs reading, the linearity of TLDs was assessed. To estimate and draw the linearity graph of TLDs, 24 TLDs were selected randomly, and divided into eight groups then irradiated in the photon mode of the Elekta Precise linac $(6 \mathrm{MeV})$ in the range of 110 to $250 \mathrm{cGy}$. The linearity function was estimated and applied to the numbers which read larger than 1 Gy. Table 2 and Figure 3 represent the number and TLD's linearity graph.

\section{Experimental dosimetry in Rando Phantom}

Given that some articles have reported TPS weakness in estimating doses of outfield organs [20-23], TLDs were chosen to measure the point doses in organs outside the treatment fields. Nine organs (right and left lenses, thy-

Table 2: TLDs results in TLDs linearity calibration.

\begin{tabular}{ccccccccc} 
& Group 1 & Group 2 & Group 3 & Group 4 & Group 5 & Group 6 & Group 7 & Group 8 \\
\hline Radiation Dose (cGy) & 110 & 130 & 150 & 170 & 190 & 210 & 230 & 250 \\
\hline Reading Dose (cGy) & 109.8 & 127.77 & 151.30 & 178.64 & 185.80 & 224.07 & 240.90 & 260.00
\end{tabular}

roid, right and left lung, right and left kidney, spinal cord, heart and liver, bladder, rectum, uterine) were located in Rando phantom's slices and 48 TLDs were placed on the designated position inside organs in different slices of Rando phantom. Based on the organ volume, at least two TLDs were placed in each organ. Thereafter, eight plans applied to Rando phantom with ISOgray TPS were undertaken for Rando phantom. Measurements were repeated three times for greater accuracy.

\section{Results}

The point dose measurement in Rando phantom for all eight plans was carried out by ther-

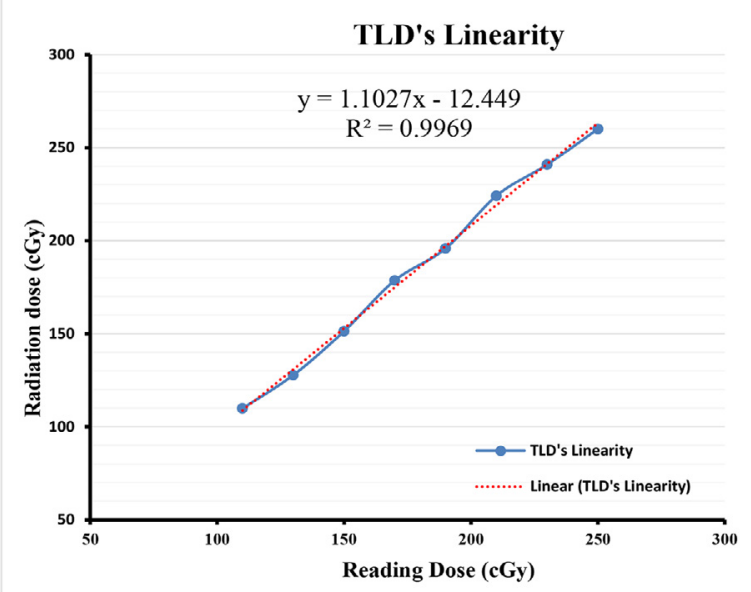

Figure 3: TLD's linearity graph. 
moluminescence chips. The results of measurements are demonstrated in Table 3 based on the organ point dose which were out of treatment fields. The numbers in Table 3 show the mean and standard deviation of three-time measurement and the number is based on 50 gray in 25 fraction (2 Gy per fraction). For all numbers, TLDs' background doses deducted from the primary TLD's absorbed dose and for larger than 1 Gy were inserted in the linearity function to compute the dose. All of these were undertaken to obtain accurate doses absorbed

Table 3: Organ point doses ( $m G y$ ) measurement in Rando phantom for different techniques of breast cancer radiation treatment ( $50 \mathrm{~Gy}$ in 25 Fraction)

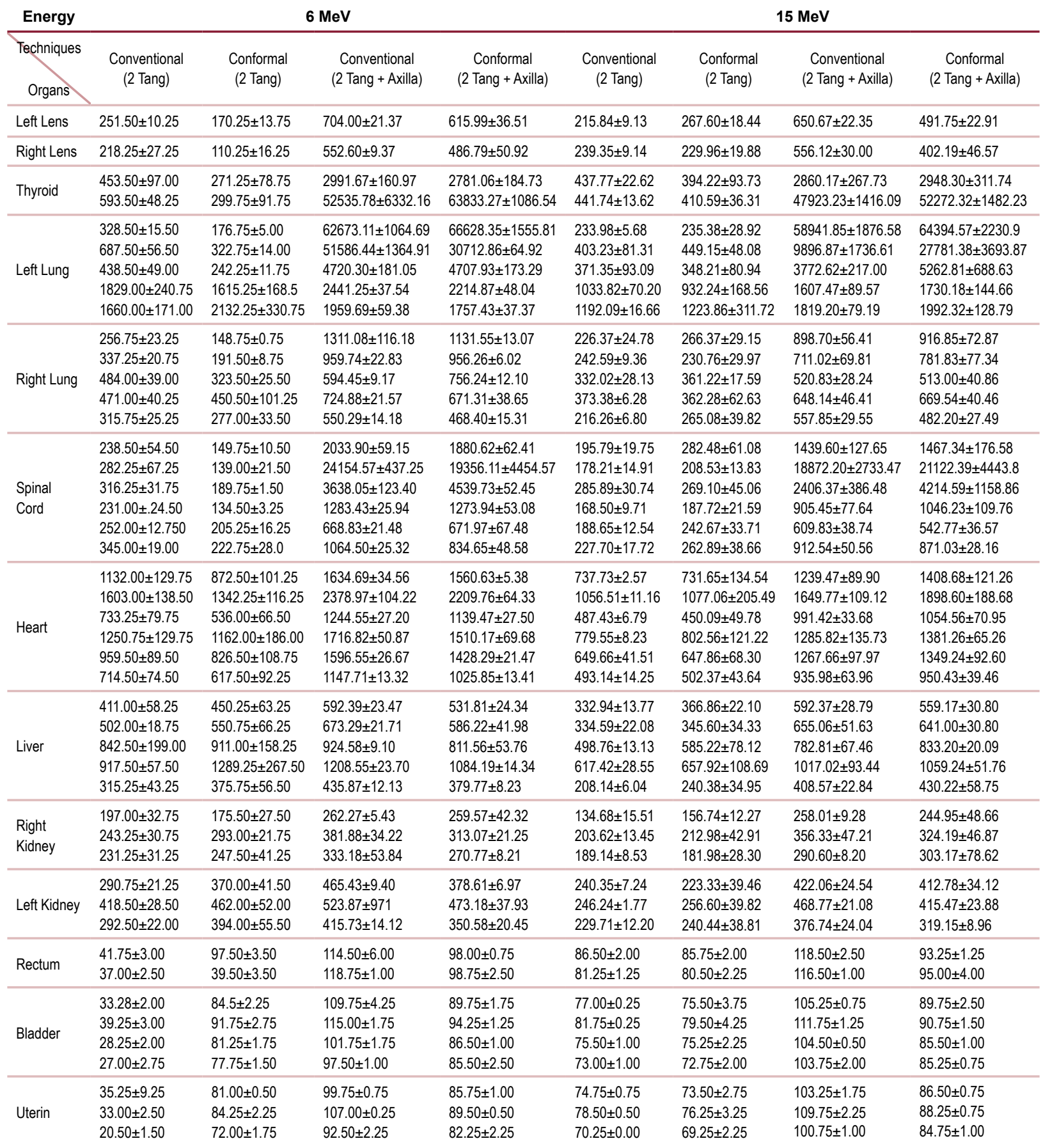


by organs. The point doses were assigned to two primary groups based on the Elekta linac energy (photon mode) and then each group was further divided into four subgroups based on the treatment techniques. In this table, the dimensions of absorbed doses are expressed in milli-Gray (mGy). Figure 4 depicts the glow curve of TLD reading, the first and second plots are glow curves for two TLDs in outfield organs and the third plot is the glow curve for a background TLD which is exported from Harshaw TLD reader (Model 3500).

\section{Discussion}

In this study, considering the importance of secondary cancer estimation in out-of-field organs in patients who have radiation therapy treatment, the outfield point dose of organs was measured for radiation treatment of breast cancer. According to articles evaluating secondary cancer $[8,24-28]$, the first and important parameter for assessing secondary cancer is absorbed dose in out of radiation fields. In general, the results in this study represent that the point doses of organs closer to treatment fields in comparison with organs distant from treatment fields are larger. It is clear that in paired organs, like eyes and kidneys, the left organ absorbs higher dose. This is obviously related to the inverse-square law.

Plans of $6 \mathrm{MeV}$ energy: As expected, the results suggest that point dose of organs in conventional treatment plans is higher than conformal ones and then TLDs in plans with super clave and postaxilla fields besides tangential fields (4 treatment fields) absorbed greater dose compared to plans with two tangential fields (especially in organs close to the treatment fields such as left-lung, spinal cord and heart). The above results could be explained as follows: treatment fields in conventional plans are wider than that of conformal ones; on the other hand, the multi-leaf collimator, which covers critical organs in conformal plans, produces more scatter photons in treatment fields. The results of conventional and conformal
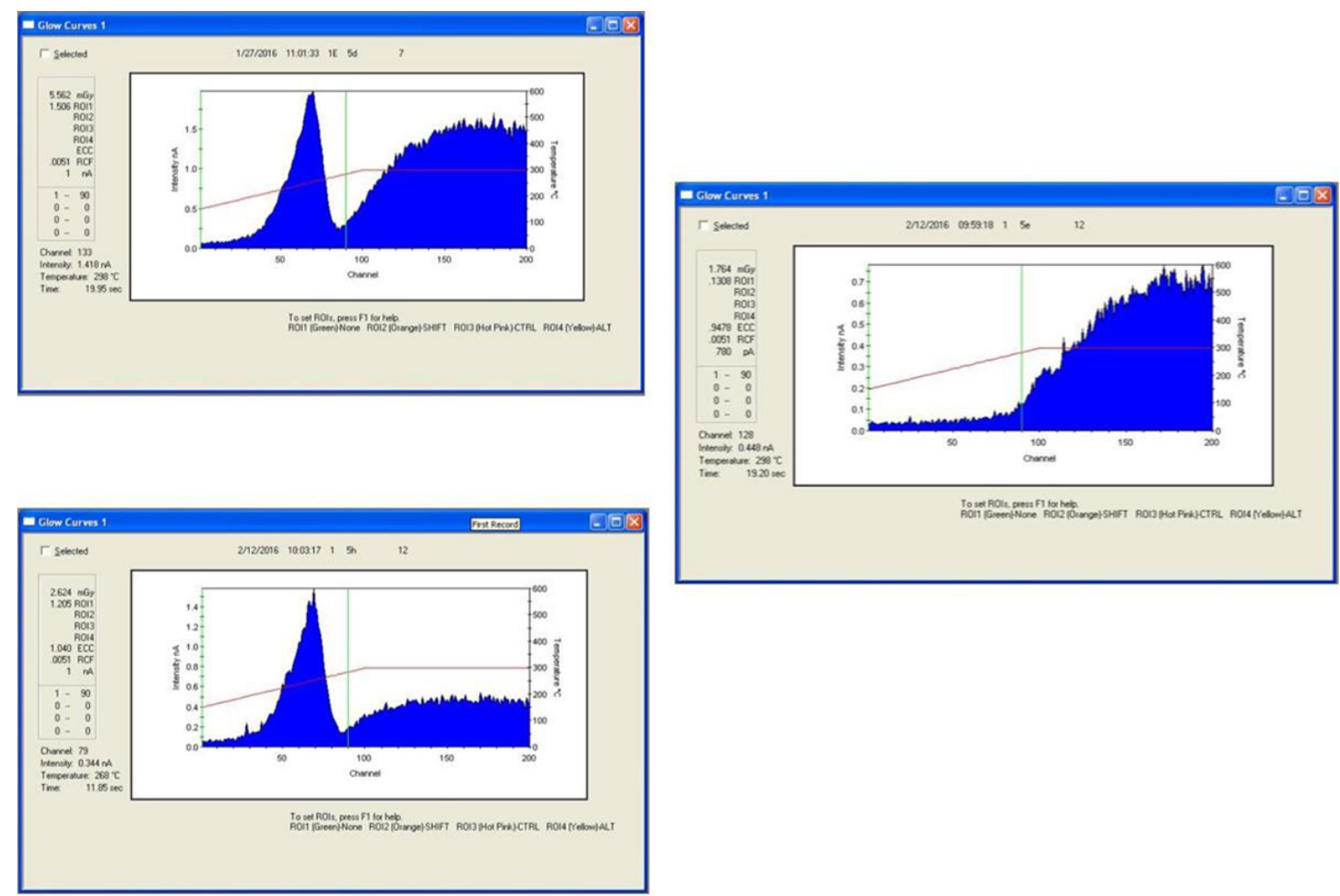

Figure 4: TLDs glow curve a) and b) TLDs which are in Rando Phantom's organs. c) background TLDs. 
techniques for $6 \mathrm{MeV}$ photon energy indicate that scattering caused by the treatment field size in conventional plans is more effective than the scattering induced by the MLC.

Plans of $15 \mathrm{MeV}$ energy: The point dose of organs in conventional and conformal plans (2 tangential fields) with $15 \mathrm{MeV}$ photon energy provided relatively identical outcomes which could be attributed the following factors: 15 $\mathrm{MeV}$ photon energy has greater penetration depth and lower scattering than $6 \mathrm{MeV}$ energy [29]. Therefore, conventional and conformal plans with $15 \mathrm{MeV}$ energy have lower scattering in outfield organs confirming the results by comparing the columns related to $6 \mathrm{MeV}$ and $15 \mathrm{MeV}$ energy plans, respectively. On the other hand, the effect of MLC in conformal plans with $15 \mathrm{MeV}$ energy leads to greater scattering. Thus, it is expected that point doses of organs in these plans (conformal and conventional with 2 tangential fields) will be the same, while other plans with 4 treatment fields in this energy follow the same role in plans with $6 \mathrm{MeV}$ photon energy.

The presence of wedge in plans of $6 \mathrm{MeV}$ is another reason for higher organ point dose in these plans compared to $15 \mathrm{MeV}$ energy. Other sources of scattering are the presence of shield in the super clave and postaxilla treatment fields.

As seen in the results, with increasing the photon energy, the medical physicist has the reasonable dose distribution and dose volume histogram (DVH) with omitting the wedge in phantom plans. On the other hand, using the high energy photon is imposed neutron contamination to the plans. Under this condition, if the medical physicists cover target with an acceptable dose distribution by $6 \mathrm{MeV}$ photon energy and wedge, the use of subfield instead of wedge can be a good suggestion. This suggestion can help to reduce the photons scattering in $6 \mathrm{MeV}$ plans without having neutron contamination.

The finding in this study is comparable with the results in Berris et al. (2012) [6] study in some organs. Their measurement was in a single energy ( $6 \mathrm{MeV}$ energy) and single technique. The authors measured absorbed dose in a Rando phantom's organs which are treated for breast cancer with tangential fields (two size) and reported the mean dose in organs. Their outcomes approved results of study in common organs and condition.

\section{Conclusion}

Selection of energies and techniques for radiotherapy treatment of breast cancer have a big effect on scatter absorbed dose (which due to the wedge, shields and MLC beside the other common scattering sources) in out of field organs. However, we should consider that this selection is dependent on different factors like the volume of breast, the number of lymph nodes which involved to cancer and the depth of chest wall that need to be treated by the medical oncologist. Therefore, for election of treatment, all those factors and source of scatters should be evaluated.

\section{Acknowledgment}

The authors would like to thank the radiotherapy department of Imam Reza hospital (Mashhad, Iran) for providing experimental measurement conditions. The results of this study are based on the data derived from a $\mathrm{PhD}$ thesis by Marziyeh Behmadi (grant $\mathrm{n}$. 931169), which was funded by Mashhad University of Medical Sciences (MUMS).

\section{Conflict of Interest}

None

\section{References}

1. Ferlay J, Autier P, Boniol M, Heanue M, Colombet M, Boyle P. Estimates of the cancer incidence and mortality in Europe in 2006. Ann Oncol. 2007;18:581-92. doi: 10.1093/annonc/mdl498. PubMed PMID: 17287242.

2. Ghoncheh M, Pournamdar Z, Salehiniya H. Incidence and Mortality and Epidemiology of Breast Cancer in the World. Asian Pac J Cancer Prev. 2016;17:43-6.doi: 10.7314/apjcp.2016.17.s3.43 . PubMed PMID: 27165206. 
3. Clegg LX, Reichman ME, Miller BA, Hankey BF, Singh GK, Lin YD, et al. Impact of socioeconomic status on cancer incidence and stage at diagnosis: selected findings from the surveillance, epidemiology, and end results: National Longitudinal Mortality Study. Cancer Causes Control. 2009;20:417-35. doi: 10.1007/s10552-008-9256-0. PubMed PMID: 19002764; PubMed Central PMCID: PMC2711979.

4. Berry DA, Cronin KA, Plevritis SK, Fryback DG, Clarke L, Zelen $M$, et al. Effect of screening and adjuvant therapy on mortality from breast cancer. N Engl J Med. 2005;353:1784-92. doi: 10.1056/ NEJMoa050518. PubMed PMID: 16251534.

5. Kalager M, Haldorsen T, Bretthauer M, Hoff G, Thoresen SO, Adami HO. Improved breast cancer survival following introduction of an organized mammography screening program among both screened and unscreened women: a population-based cohort study. Breast Cancer Res. 2009;11:R44. doi: 10.1186/bcr2331. PubMed PMID: 19575807; PubMed Central PMCID: PMC2750103.

6. Berris T, Mazonakis M, Stratakis J, Tzedakis A, Fasoulaki A, Damilakis J. Calculation of organ doses from breast cancer radiotherapy: a Monte Carlo study. J Appl Clin Med Phys. 2013;14:4029. doi: 10.1120/jacmp.v14i1.4029. PubMed PMID: 23318389; PubMed Central PMCID: PMC5713920.

7. Sant M, Allemani C, Santaquilani M, Knijn A, Marchesi F, Capocaccia R, et al. EUROCARE-4. Survival of cancer patients diagnosed in 1995-1999. Results and commentary. Eur J Cancer. 2009;45:93191.doi: 10.1016/j.ejca.2008.11.018.

8. D'Arienzo M, Masciullo SG, de Sanctis V, Osti MF, Chiacchiararelli L, Enrici RM. Integral dose and radiation-induced secondary malignancies: comparison between stereotactic body radiation therapy and three-dimensional conformal radiotherapy. Int J Environ Res Public Health. 2012;9:422340. doi: 10.3390/ijerph9114223. PubMed PMID: 23202843; PubMed Central PMCID: PMC3524624.

9. Joosten A, Bochud F, Baechler S, Levi F, Mirimanoff RO, Moeckli R. Variability of a peripheral dose among various linac geometries for second cancer risk assessment. Phys Med Biol. 2011;56:513151. doi: 10.1088/0031-9155/56/16/004. PubMed PMID: 21775792.

10. Schneider U. Mechanistic model of radiationinduced cancer after fractionated radiotherapy using the linear-quadratic formula. Med Phys. 2009;36:1138-43. doi: 10.1118/1.3089792. PubMed PMID: 19472619.

11. Sharma DS, Animesh, Deshpande SS, Phurailatpam RD, Deshpande DD, Shrivastava SK, et al.
Peripheral dose from uniform dynamic multileaf collimation fields: implications for sliding window intensity-modulated radiotherapy. $\mathrm{Br} J \mathrm{Ra}$ diol. 2006;79:331-5. doi: 10.1259/bjr/16208090. PubMed PMID: 16585727.

12. Banaee N, Nedaie H, Esmati E, Nosrati H, Jamali M. Dose measurement outside of radiotherapy treatment field (Peripheral dose) using thermoluminesent dosimeters. International Journal of Radiation Research. 2014;12:356.

13. SIJI CT, Musthafa M, GANAPATHI RR, ABDUL HK, Bhasi S. Out-of-field photon dosimetry study between 3-D conformal and intensity modulated radiation therapy in the management of prostate cancer. 2015.

14. Nilsson B, Sorcini B. Surface dose measurements in clinical photon beams. Acta Oncol. 1989;28:53742.doi: $10.3109 / 02841868909092265$. PubMed PMID: 2789832.

15. Yoon J, Heins D, Zhao X, Sanders M, Zhang R. Measurement and modeling of out-of-field doses from various advanced post-mastectomy radiotherapy techniques. Phys Med Biol. 2017;62:9039-53. doi: 10.1088/1361-6560/aa94b5. PubMed PMID: 29048329; PubMed Central PMCID: PMC5724526.

16. Ghitulescu Z, Stochioiu A, Dumitrache M. Dose measurements in teletherapy using thermoluminescent dosimeters. Rom Rep Phys. 2011;63:7006.

17. Akpochafor MO, ADENEYE SO, Habeebu MY, OMOJOLA A, Adedewe N, Adedokun A, et al. Organ dose measurement in CT using thermoluminescence dosimeter in a locally developed phantom. Iranian Journal of Medical Physics. 2018.

18. Ernst M, Manser P, Dula K, Volken W, Stampanoni MF, Fix MK. TLD measurements and Monte Carlo calculations of head and neck organ and effective doses for cone beam computed tomography using 3D Accuitomo 170. Dentomaxillofac Radiol. 2017;46:20170047. doi: 10.1259/dmfr.20170047. PubMed PMID: 28749697; PubMed Central PMCID: PMC5988186.

19. Huang JY, Followill DS, Wang XA, Kry SF. Accuracy and sources of error of out-of field dose calculations by a commercial treatment planning system for intensity-modulated radiation therapy treatments. J Appl Clin Med Phys. 2013;14:4139. doi: 10.1120/jacmp.v14i2.4139. PubMed PMID: 23470942; PubMed Central PMCID: PMC5714363.

20. Howell RM, Scarboro SB, Kry SF, Yaldo DZ. Accuracy of out-of-field dose calculations by a commercial treatment planning system. Phys Med Biol. 2010;55:6999-7008. doi: 10.1088/0031- 
9155/55/23/S03. PubMed PMID: 21076191; PubMed Central PMCID: PMC3152254.

21. Joosten $A$, Matzinger 0 , Jeanneret-Sozzi $W$, Bochud F, Moeckli R. Evaluation of organ-specific peripheral doses after 2-dimensional, 3-dimensional and hybrid intensity modulated radiation therapy for breast cancer based on Monte Carlo and convolution/superposition algorithms: implications for secondary cancer risk assessment. Radiother Oncol. 2013;106:33-41.doi: 10.1016/j. radonc.2012.11.012.

22. Bahreyni Toossi MT, Soleymanifard S, Farhood B, Mohebbi S, Davenport D. Assessment of accuracy of out-of-field dose calculations by TiGRT treatment planning system in radiotherapy. $J$ Cancer Res Ther. 2018;14:634-9. doi: 10.4103/09731482.176423. PubMed PMID: 29893331.

23. Huang JY, Followill DS, Wang XA, Kry SF. Accuracy and sources of error of out-of field dose calculations by a commercial treatment planning system for intensity-modulated radiation therapy treatments. J Appl Clin Med Phys. 2013;14:4139. doi: 10.1120/jacmp.v14i2.4139. PubMed PMID: 23470942; PubMed Central PMCID: PMC5714363.

24. Schneider U, Kaser-Hotz B. Radiation risk estimates after radiotherapy: application of the organ equivalent dose concept to plateau dose-response relationships. Radiat Environ Biophys. 2005;44:235-9. doi: 10.1007/s00411-005-0016-1. PubMed PMID: 16273381.

25. Schneider U, Lomax A, Lombriser N. Comparative risk assessment of secondary cancer incidence after treatment of Hodgkin's disease with photon and proton radiation. Radiat Res. 2000;154:382-8. doi: 10.1667/0033-7587(2000)154[0382:craosc]2. 0.co;2. PubMed PMID: 11023601.

26. Schneider U, Lomax A, Timmermann B. Second cancers in children treated with modern radiotherapy techniques. Radiother Oncol. 2008;89:13540. doi: 10.1016/j.radonc.2008.07.017. PubMed PMID: 18707783.

27. Schneider U, Sumila M, Robotka J. Site-specific dose-response relationships for cancer induction from the combined Japanese A-bomb and Hodgkin cohorts for doses relevant to radiotherapy. Theor Biol Med Model. 2011;8:27. doi: 10.1186/17424682-8-27. PubMed PMID: 21791103; PubMed Central PMCID: PMC3161945.

28. Schneider U, Zwahlen D, Ross D, Kaser-Hotz B. Estimation of radiation-induced cancer from three-dimensional dose distributions: Concept of organ equivalent dose. Int J Radiat Oncol Biol Phys. 2005;61:1510-5. doi: 10.1016/j. ijrobp.2004.12.040. PubMed PMID: 15817357.

29. Knoll GF. Radiation detection and measurement. New Jersey: John Wiley \& Sons; 2010. 